\title{
DETERMINACIÓN DE MORFOTIPOS NATIVOS DE Rhizobium ASOCIADOS A LA LEGUMINOSA Teramnus volubilis Sw EN FINCAS GANADERAS DEL MUNICIPIO DE TOLÚ EN EL DEPARTAMENTO DE SUCRE
}

\section{MORPHOTYPE DETERMINATION OF NATIVE TO Rhizobium LEGUME Teramnus volubilis Sw ON CATTLE FARM IN THE MUNICIPALITY OF TOLU THE DEPARTMENT OF TO SUCRE}

\author{
PEREZ, C. ALEXANDER Dr. ${ }^{*}$, GRISALES, O. TATIANA Biol. ${ }^{1}$, FUENTES, \\ B. JULIO Biol. ${ }^{1}$ \\ ${ }^{1}$ Docente Universidad de Sucre, líder grupo de investigación en \\ Bioprospección Agropecuaria, Universidad de Sucre, ${ }^{2}$ Biólogos, Universidad \\ de Sucre. \\ *Correspondencia: alexpcor@yahoo.com
}

Recibido: 16-11- 2010; Aceptado: 20-03- 2011.

\section{Resumen}

El presente estudio se realizó, en fincas ganaderas del municipio de Tolú, Departamento de Sucre, Colombia, establecidas con la leguminosa Teramnus volubilis, con el objetivo de identificar los morfotipos de bacterias fijadoras de nitrógeno del género Rhizobium nativas asociados a esta especie. Fueron evaluadas las características de los nódulos formadas en las raíces de la leguminosa, encontrándose formas redondeadas con coloraciones internas (rojas, verde oscuro y blanco) y externas (café claro y café oscuro), un número de nódulos/raíz de medio a alto, con tamaño variado y amplia distribución en raíces secundarias. La densidad poblacional de Rhizobium determinada en medio de cultivos arrojó un alto número de colonias $\left(22 \times 10^{8} \mathrm{UFC} / \mathrm{ml}\right)$ en la zona de Pita Abajo, en contraste a la densidad hallada en la zona de Santa Lucía de $\left(15 \times 10^{8} \mathrm{UFC} / \mathrm{ml}\right)$. Se realizaron 28 aislamientos de los cuales 14 compartieron características del género Rhizobium. Los resultados del Análisis de Correspondencias Múltiples clasificaron los aislamientos en 5 grupos de morfotipos de Rhizobium, teniendo en cuenta la morfología, tamaño y color de las colonias. El Análisis de clúster aglomerativo mostró 4 grupos de aislamientos basada en los contenidos de fosforo y la capacidad de intercambio catiónico de los suelos y el número de nódulos formado. El presente estudio muestra que 
existe una alta diversidad de bacterias del géneros Rhizobium asociadas a raíces de Teramnus volubilis en condiciones edáficas de los suelos del municipio de Tolú.

Palabras claves: leguminosa, nodualación, Rhizobium, suelo

\begin{abstract}
This study was conducted in cattle farms in the municipality of Tolú, Sucre Department, Colombia, established with the legume Teramnus volubilis, to identify the morphotypes of nitrogen-fixing bacteria of the genus Native Rhizobium associated to this specie. To do this it was necessary to evaluate the characteristics of the nodules formed on legume roots, being rounded forms internal colours (red, dark green and white) and external (light brown and dark brown), number of nodules /root medium to high, with varying size and wide distribution in secondary roots. The population density of specific Rhizobium in culture medium showed a high number of colonies $\left(22 \times 10^{8}\right.$ CFU / ml) in the area of Pita Abajo, in contrast to the density found in the Santa Lucia $\left(15 \times 10^{8} \mathrm{CFU} / \mathrm{ml}\right) .28$ isolates were made of which 14 shared characteristics of the genus Rhizobium. The results of the Multiple Correspondence Analysis of isolates classified in five groups of morphotypes of Rhizobium, taking into account the morphology, size and colour of the colonies. The agglomerative cluster analysis showed four groups of isolates based on the contents of phosphorus and cation exchange capacity of soils and the number of nodules formed. This study shows there is a high diversity of Rhizobium bacteria associated with roots of Teramnus volubilis in soil conditions of the soil of the town of Tolú.
\end{abstract}

Key words: legume, nodulation, Rhizobium, soil

\title{
Introducción
}

La ganadería doble propósito es la principal actividad económica del Departamento de Sucre, en el cual el $84.9 \%$ de su territorio está dedicado exclusivamente al pastoreo de ganado donde la fuente exclusiva de alimento animal la constituyen las leguminosas forrajeras nativas y las gramíneas (VIOLRIA, 2003; AGUILERA, 2005). En el grupo de leguminosas forrajeras predominantes en el Departamento de Sucre se destaca el bejuco de chivo (Teramnus volúbilis Sw); por crecer silvestre en las fincas y ser nativa, además vive en una amplia gama de suelos y se establece rápidamente, es 
resistente a la sequía, pisoteo y ataque de nematodos, manteniéndose verde durante la época de lluvias y es alternativa de alimentación por constituirse en un buen forraje para bovinos y equino ya que contiene un $16.83 \%$ de proteína bruta (BERMÚDEZ, 1973). Además, contribuye al manejo sostenible de la tierra ya que ayudan a regenerar los suelos degradados, reducir la erosión y controlar las plantas indeseables.

Los suelos de las fincas ganaderas del Departamento de Sucre, se caracterizan por tener altos niveles de compactación, erosión, bajos niveles de fertilidad y uso indiscriminado de agroquímicos, dando como resultado praderas degradadas, con baja producción y oferta de forraje con bajos contenidos nutricionales. Los suelos de Tolú tienen un relieve plano, sujetos a inundaciones, niveles de fertilidad y saturación de bases de mediana a alta, y cantidades variables de sodio (ESPITIA y MARTíNEZ, 2003). Sin embargo, en estos suelos existen unas bacterias simbióticas denominadas Rhizobium, las cuales permiten la obtención de biológica de nutrientes nitrogenados a las leguminosas, contribuyendo así con una parte considerable del nitrógeno combinado en la tierra, permitiendo a las plantas leguminosas crecer sin fertilizantes nitrogenados y sin empobrecer los suelos (MARTíNEZ y LÓPEZ, 2000).

Por tal motivo, las leguminosas forrajeras juegan un papel importante en la producción agropecuaria como fuente alternativa de alimento para el ganado. Estas es consideradas en la ag ultura sostenible como cultivo de importancia en el sistema de rotación y en la reducció de la fertilización nitrogenada debido a su capacidad de formar simbiosis con bacterias diazotróficas del genero Rhizobium y fijar nitrógeno atmosférico, lo que les confiere un efecto beneficioso en los cultivos (PERALTA, 2002). En general se ha estimado que la simbiosis leguminosa - Rhizobium tiene un potencial de fijación entre $52-320 \mathrm{Kg} / \mathrm{N} / \mathrm{ha}$ dependiendo de la planta y de las condiciones ambientales (CIAT, 1987).

Sin embargo no todos los suelos agrícolas poseen las bacterias del género Rhizobium u otras simbióticas necesarias para promover un desarrollo adecuado en las leguminosas y algunas de estas plantas requieren asocios específicos con esta bacteria para producir buenos resultados en cuanto a la fijación del nitrógeno. Es así, como cada leguminosa necesita su propia cepa especifica de rhizobios para formar eficientemente nódulos de nitrógeno en sus raíces (STODDARD, 1975). 
Las investigaciones actuales en microbiología del suelo están encaminadas a descubrir el papel que juegan los microorganismos en los fenómenos degradativos que ocurren en el seno del suelo y poner en evidencia la especie o grupos de especies de microorganismos que participan en ellos ya que estos pueden utilizar en el suelo, todas las materias orgánicas que se hallen presentes (KEENEY y NELSON, 1982). Estudios que se han realizado con Rhizobium indican que las razas nativas de bacterias de leguminosas más efectivas pueden aumentar el contenido o el rendimiento de proteína en estas hasta un $20 \%$ más en cultivos de leguminosas tradicionales como lentejas, chícharo, garbanzo, soya, fríjol y leguminosas de pradera (ERDMAN, 1968).

Debido a los problemas planteados y que hasta la fecha no se han reportado los tipos de Rhizobium nativos de los suelos del Departamento de Sucre, este trabajo contribuye a determinar los principales morfotipos de Rhizobium asociados a la especie Teramnus volubilis Sw, y así crear un punto de partida de futuras investigaciones en el ámbito genético, fisiológico, ecológico, bioquímico y a su uso como biofertilizante en cultivos de importancia económica para la ganadería, mejorando así el forraje consumido por el ganado incrementándose las producciones, ya que en los sistemas de pastoreo las leguminosas son la mayor y más barata fuente de proteína para el ganado de carne y leche, generando divisas a través de la producción animal. Dada la importancia de las leguminosas forrajeras en el sistema agropecuario de la región, se planteó determinar los diferentes morfotipos de Rhizobium asociados a la leguminosa Teramnus volubilis Sw en fincas ganaderas de Tolú, en el Departamento de Sucre, Colombia.

\section{Materiales y métodos}

\section{Sitio de estudio}

El presente estudio fue realizado en fincas ganaderas del municipio de Tolú, Departamento de Sucre. Este municipio se encuentra localizado en el noroccidente del Departamento en la denominada llanura costera aluvial del Golfo del Morrosquillo, a $9^{\circ} 31^{\prime}$ latitud norte y $75^{\circ} 35^{\prime}$ longitud oeste a 3.0 msnm, con temperatura promedio de $28^{\circ} \mathrm{C}$ y precipitación pluvial anual de 500-1200 mm. La estación lluviosa va desde finales de abril hasta finales de noviembre, con algunas disminuciones sustanciales entre junio y agosto, 
denominado veranillo de San Juan; la época seca tiene duración aproximada de 5 meses (Diciembre-Abril). La formación vegetal corresponde al bosque seco tropical, se encuentra en clima cálido seco, los materiales que conforman los suelos están constituidos por sedimentos aluviales, marinos o combinaciones de los dos. En algunos sectores hay sedimentos orgánicos (INSTITUTO GEOGRÁFICO AGUSTÍN CODAZZI, 1998).

\section{Muestreo}

El muestreo se llevó a cabo en fincas ganaderas establecidas con la leguminosa Teramnus volubilis ubicadas según el plan de Ordenamiento Territorial y el Instituto Geográfico Agustín Codazzi, en cinco zonas (Tabla 1).

Tabla 1. Zonas y Fincas Ganaderas del municipio de Tolú establecidas con Teramnus volubilis.

\begin{tabular}{|c|c|c|}
\hline Zona & Corregimiento & $\begin{array}{c}\text { № Fincas con Teramnus } \\
\text { volubilis }\end{array}$ \\
\hline 1 & Nueva Era & 7 \\
\hline 2 & Cabecera Municipal & 8 \\
\hline 3 & Pita Abajo & 6 \\
\hline 4 & Santa Lucia & 5 \\
\hline 5 & Puerto Viejo & 7 \\
\hline Total & & 33 \\
\hline
\end{tabular}

En las fincas ganaderas seleccionadas aleatoriamente, se realizó un muestreo representativo tomando entre $15-20$ submuestras al azar siguiendo un patrón en $\mathrm{W}$ o zig-zag a una profundidad de $5-20 \mathrm{~cm}$, tomando al tiempo suelo y raíces para evitar desecamiento de los nódulos. Posteriormente se llevaron las submuestras a bolsas plásticas individuales y se rotularon con el número de la muestra, ubicación y fecha de recolección (ESPITIA y MARTÍNEZ, 2003). A cada muestra de suelo se hizo análisis físico-químico de suelos, caracterización y salinidad y microbiológico. A cada finca muestreada se le diligenció un formato encuesta.

\section{Análisis microbiológico.}


Las muestras de suelo fueron colocadas en un balde con agua por un periodo de tiempo de 3 a 5 días, para la disolución del mismo. Posteriormente se retiraron las raíces y se lavaron. Cada raíz por separado, fue observada en estereoscopio para determinar el tamaño de los nódulos, distancia entre ellos; el color tanto interno como externo; el número de nódulos y su distribución en la raíz (RAMíREZ, 1992). Una vez analizados fueron retirados de la raíces para posterior aislamientos en medios de cultivos de bacterias del géneros Rhizobium (WEAVER y GRAHAM, 1994). El aislamiento de los diferentes morfotipos de Rhizobium fue realizada, utilizando mediante tecnica propuesta por CIAT (1997), la cual consistió en el lavado de los nódulos, desinfección mediante sumersión en solución de hipoclorito de sodio $\left(\mathrm{NaClO}_{3} 4 \%\right)$ por 4 a 5 minutos. Posteriormente se colocaron los nódulos en agua estéril por 1-2 minutos y se repitió la operación por siete veces para asegurar una total limpieza de residuos de hipoclorito de sodio en la superficie de los nódulos. Los nódulos desinfectados fueron colocados en mortero estéril y se maceraron para obtener la liberación de los bacteroides. Con ayuda de una micropipeta se agregaron $200 \mu \mathrm{l}$ de la solución de macerado en cajas de petri (tres replicas por muestra) con el medio A.L.M, esparcieron y se incubaron la siembra a $37^{\circ} \mathrm{C}$ por un tiempo de 2-9 días. Se realizaron nuevos aislamientos a partir del cultivo inicial hasta obtener un cultivo puro de Rhizobium (RAMíREZ, 1992).

Para la identificación del género Rhizobium se utilizó la técnica de tinción de Gram, la cual permitió observar la característica de Gram-negativas y las diferentes morfologías presentadas por las bacterias. Se realizó prueba de confirmación, la cual consistió en tomar muestra del cultivo en un portaobjeto y se le agregó una gota de azul de bromotimol, si se observa un cambio a amarillo se comprueba la presencia de Rhizobium, en caso negativo corresponde a Bradyrhizobium (RAMÍREZ, 1992). Para determinar la población de Rhizobium presente en las muestras de las diferentes fincas se realizaron diluciones seriadas de los nódulos. Se tomaron $0.2 \mathrm{ml}$ de macerado y se depositaron en tubos con caldo Triptófano enriquecido con extracto de levadura y glucosa e incubación de la siembre por 3 a 5 días, a $30^{\circ} \mathrm{C}$ de acuerdo a metodología propuesta por ALAMI et al., (2000). Una vez obtenido el aislamiento, la muestra se agitó y se prepararon diluciones seriadas de $10^{-1}$ a $10^{-10}$. A partir de la dilución $10^{-6}$ y por triplicado, se sembraron alícuotas de $1 \mathrm{ml}$ en medio Y.M.A, se incubaron a temperatura de $30^{\circ} \mathrm{C}$ de 2-5 días. La densidad población se determinó fue determinado mediante 
conteo de colonia en placas y la densidad final fue expresad en UFC/mL (VALENZUELA y SILVESTRE, 1991).

\section{Análisis estadístico}

Para correlacionar características culturales entre los diferentes morfotipos aislados (forma, color, tamaño) por zonas, aplicó análisis de correspondencias múltiples y de componentes principales (APC) en programa SAS 6.1.2 (Statistical Analysis System). Para obtener grupos de características compatibles entre los morfotipos, fue realizado el análisis de clúster aglomerativo de distancias euclidianas ligado al método de Ward. Para predecir el establecimiento de Rhizobium por tipo de suelo, se hizo agrupamiento de morfotipos en relación al número de nódulos formados por zona y en función de los parámetros físico-químicos del suelo de las diferentes zonas estudiadas fue realizada mediante análisis de componentes principales.

\section{Resultados}

De acuerdo a los resultados de los análisis físico-químicos, los suelos de las fincas objetos del presente estudio, presentaron un rango de $\mathrm{pH}$ de moderadamente ácido a moderadamente alcalino, contenido de materia orgánica de media a alta (2.8-5.8\%), porcentaje de fosforo de alto a muy excesivo, cantidad de potasio de medio a alto, magnesio de alto a muy alto, sodio de medio a alto al igual que el elemento Calcio, textura de franco arenosa en su mayoría a franco y franco arcillosa. Al momento del muestreo en estas fincas había realizado aplicación de agroquímicos y fertilización. Entre los productos químicos de mayor uso, se encuentra la Urea, herbicidas, Mina 780, Round up y Galope en aspersión. Los resultados de las encuestas diligenciadas a cada finca muestreada, indica que la mayoría de las fincas analizadas, presentan un relieve plano, con suelos agrietados y tendencia a encharcarse durante el periodo de lluvias. La leguminosa Teramnus volubilis se encuentra en estado de fructificación principalmente en los meses de Febrero a Marzo y, al finalizar el mes de Junio se observa en estado vegetativo, sin semillas ni flores y enredadas al pasto angletón. 
Los nódulos encontrados presentaron una forma redondeada y su coloración externa fue similar a la de la raíz (Fig.1A), variando de café claro a café oscuro, con una superficie costrosa (Fig.1B). Su coloración interna varió de un color rojo ladrillo (Fig.1C) pasando por verde oscuro (Fig.1D) y blanco, los cuales se presentaron en gran cantidad. En cuanto al número de nódulos, en general registró valores de medio a alto en un rango mínimo promedio de 3 a 37 nódulos por raíz. El tamaño de los nódulos se encontró en un rango de medio alto $(0.76 \mathrm{~mm}$ a $1.16 \mathrm{~mm}$ de diámetro). Los nódulos se distribuyeron con mayor frecuencia en las raíces secundarias que en las primarias en proporción de 5:1.

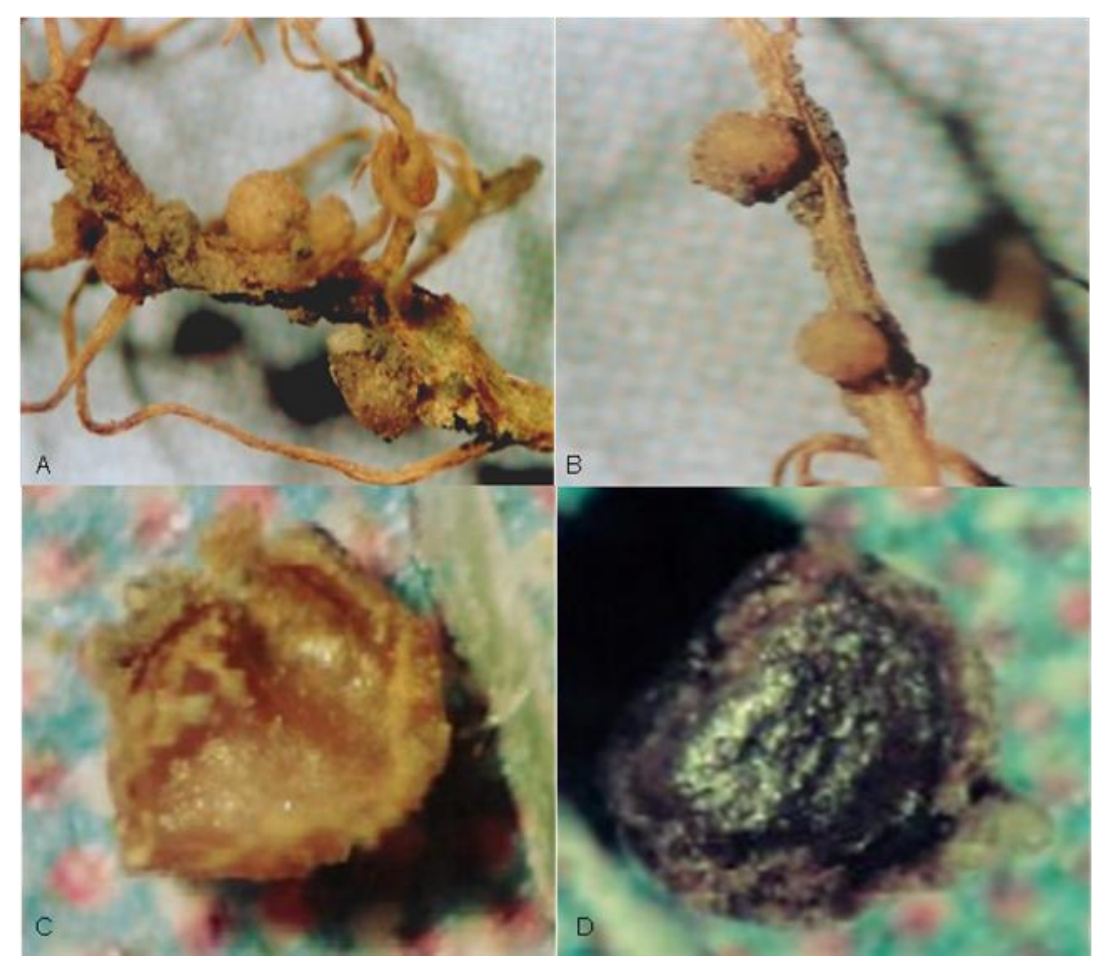

Figura 1. Características de los nódulos de Teramnus volubilis. 1: nodulo en raíz primaria

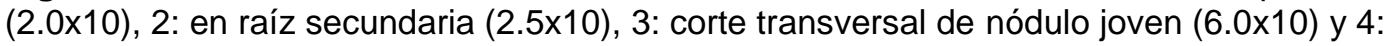
corte transversal de nódulo viejo $(3.5 \times 10)$

En Tabla 2, se observa los resultados de los cósenos cuadrados realizados a las características culturales (color, forma, ancho, largo y diámetro) de los morfotipos aislados. En la tabla, se muestra que en la dimensión 1, la variable más incidente fue la forma de la colonia y en la dimensión 2, se observa que el color de las colonias y el largo de las colonia son las características de mayor valor. 
Tabla 1. Cosenos cuadrados resultantes del Análisis de Correspondencia Múltiple

\begin{tabular}{|c|c|c|}
\hline Características & Dimensión 1 & Dimensión 2 \\
\hline Forma & $\mathbf{0 , 9 8 2 9 9 6}^{\star}$ & 0,15171 \\
\hline Color & 0,201359 & $\mathbf{0 , 7 8 7 7 8 9}^{\star}$ \\
\hline Ancho & 0,190938 & 0,123478 \\
\hline Largo & 0,097600 & $\mathbf{0 , 7 1 1 9 0 2}^{\star}$ \\
\hline Diámetro & 0,383348 & 0,201632 \\
\hline
\end{tabular}

El análisis de correspondencia múltiple realizado a partir de la información obtenida de la tabla 1, clasificó 5 grupos de morfotipos de bacterias del género Rhizobium en función a características culturas de los aislamientos (color, forma largo, ancho y diámetro) (fig. 3). En el primer grupo se observa que los morfotipos (M0001, M002 y MOO6a) están clasificados por el color de las colonias; en el grupo 2 aparecen los morfotipos (MOO4, M007 y M011a) agrupados en función del ancho y diámetros de las colonias; los morfotipos (M009 y M008) corresponden al grupo 3 clasificados por la forma, en el grupo 4 se encuentran los morfotipos (M003,M010, M012, M013a, M013b) agrupados forma y el largo y en el grupo 5 aparece un solo (MOO6b) clasificado con base a largo de la colonia (tabla 3). 


\section{Analisis de correpondencia multiple}

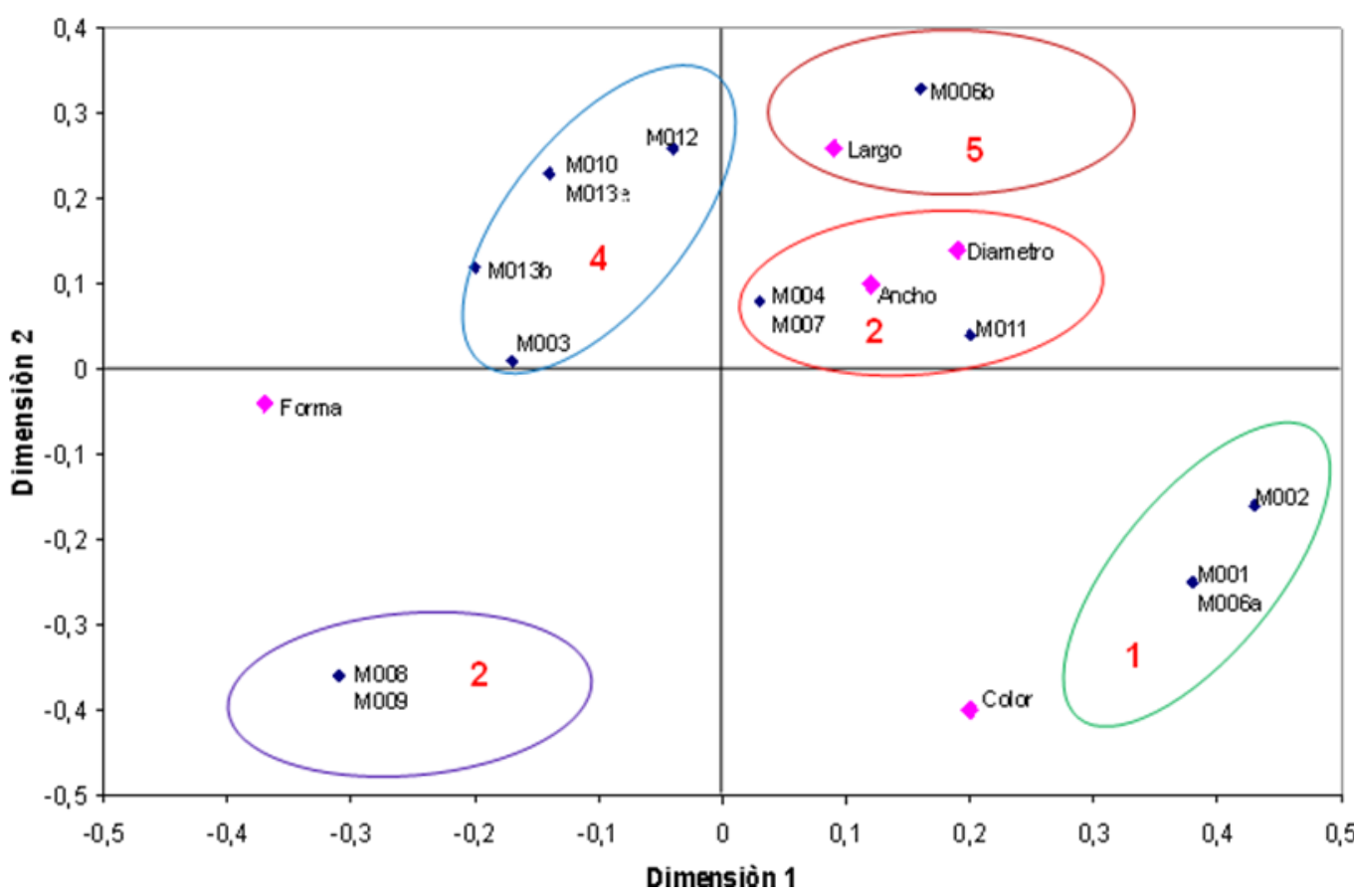

Figura 3. Agrupamiento de aislamientos de Rhizobium por características culturales mediante análisis de correspondencia múltiple

La tabla 3 , se observa que el morfotipo 1 , se caracteriza por presentar células de formas elipsoidales, tamaño de (entre1.5 $\mu \mathrm{m}-2.0 \mu \mathrm{m}$ de largo) y color blanco-crema. El morfotipo 2 contiene células de formas bacilares alargadas con colonias de diámetro $(>2 \mathrm{~mm})$ y color translúcido. El morfotipo 3 está integrado por células de formas esferoidales pequeñas (largo $<1.5 \mu \mathrm{m}$ y ancho $1 \mu \mathrm{m})$, al igual que sus colonias cuyos diámetros son $<2 \mathrm{~mm}$ y presentan un color blanco-crema. El morfotipo 4 está conformado por células de formas bacilares alargadas de gran longitud, la cual supera las $2 \mu \mathrm{m}$, con colonias de diámetro pequeño $(<2 \mathrm{~mm})$ y color blanco. El morfotipo 5 , con un único aislamiento, presenta células de formas ramificadas 0 irregulares $(x \circ$ y), grandes $>2 \mu \mathrm{m}$ y ancho $>1 \mu \mathrm{m}$, con colonias de diámetro grande $(>2 \mathrm{~mm})$ y coloración blanca. 
Tabla 3. Descripción de las características de los morfotipos de Rhizobium establecidos mediante el método estadístico del Centroide

\begin{tabular}{|c|c|c|c|c|c|c|}
\hline \multirow[b]{2}{*}{ Morfotipos } & \multirow[b]{2}{*}{ Muestra } & \multicolumn{2}{|c|}{ Macroscópicas } & \multicolumn{3}{|c|}{ Microscópicas } \\
\hline & & Diámetro & Color & Largo & Ancho & Forma \\
\hline \multirow{3}{*}{1} & M001 & 1 & 3 & 2 & 1 & 1 \\
\hline & M002 & 2 & 3 & 2 & 1 & 1 \\
\hline & M006a & 1 & 3 & 2 & 1 & 1 \\
\hline \multirow{3}{*}{2} & M004 & 2 & 2 & 3 & 1 & 3 \\
\hline & M007 & 2 & 2 & 3 & 1 & 3 \\
\hline & M011a & 1 & 1 & 1 & 1 & 1 \\
\hline \multirow{2}{*}{3} & M008 & 1 & 3 & 1 & 1 & 5 \\
\hline & M009 & 1 & 3 & 1 & 1 & 5 \\
\hline & & & & & & \\
\hline \multirow{5}{*}{4} & M003 & 1 & 2 & 3 & 3 & 1 \\
\hline & M010 & 1 & 1 & 3 & 3 & 1 \\
\hline & M012 & 2 & 1 & 3 & 1 & 3 \\
\hline & M013a & 1 & 1 & 3 & 1 & 3 \\
\hline & M013b & 1 & 1 & 2 & 1 & 3 \\
\hline & & & & & & \\
\hline 5 & M006b & 2 & 1 & 3 & 2 & 2 \\
\hline
\end{tabular}

DIÁMETRO: $1=\leq 2$, DIAMETRO 2= $\geq 2$; LARGO: $1=$ menores $\leq 1.5$, 2= entre 1.5 y 2 ; COLOR:1:

Blanco,2; traslucida, 3: blanco-crema);FORMA 1= Elipsoidales, 2= Irregulares,3= Alargadas, 4= Esferoidales, $5=$ mayores a 2; forma (ancha 1: $\leq 2$, ancho 2; $\geq 2$ )

Para establecer relación entre los diferentes morfotipos de bacterias aisladas de las raíces en función de la modulación (número de nódulos, tamaño, distancia,) y de parámetros físico-químicas del suelo $(\mathrm{pH}$, materia orgánica $(\mathrm{MO})$, fosforo $(\mathrm{P})$, capacidad de intercambio catiónico $(\mathrm{CIC})$, calcio $(\mathrm{Ca})$, magnesio $(\mathrm{Mg})$, potasio $(\mathrm{K})$ y sodio $(\mathrm{Na})$, se realizó Análisis de Componentes Principales. La tabla 4, muestra los resultados de las principales variables clasificadas, se observa que para la componente 1, el elemento Fósforo es la variable de mayor valor, así mismo se detalla que en la segunda y tercera componente, el Número de nódulos formado por raíces y la $\mathrm{CIC}$, respectivamente, fueron las variables de mayor significancia. 
Tabla 4. Vectores propios resultantes del Análisis de Componentes Principales

\begin{tabular}{|c|c|c|c|}
\hline Características & COMP 1 & COMP 2 & COMP 3 \\
\hline P & $\mathbf{0 , 9 7 3 8 6 1 ^ { * }}$ & $-0,40551$ & $-0,172844$ \\
\hline Número de nódulos & $-0,040393$ & $\mathbf{0 , 9 1 4 2 8 9 ^ { * }}$ & $-0,161061$ \\
\hline CIC & 0,143675 & 0,102640 & $\mathbf{0 , 8 3 7 8 7 8}$ \\
\hline Tamaño & $-0,002205$ & $-0,001191$ & $-0,020626$ \\
\hline Distancia & 0,072047 & 0,089207 & 0,330330 \\
\hline $\mathrm{PH}$ & $-0,009635$ & $-0,007049$ & $-0,003137$ \\
\hline $\mathrm{MO}$ & 0,023672 & 0,013764 & 0,099475 \\
\hline $\mathrm{Ca}$ & 0,054704 & 0,0737718 & 0,343663 \\
\hline $\mathrm{Mg}$ & 0,139666 & 0,370580 & $-0,010793$ \\
\hline $\mathrm{K}$ & 0,007630 & $-0,002178$ & $-0,012727$ \\
\hline $\mathrm{Na}$ & $-0,030253$ & 0,030486 & 0,065679 \\
\hline
\end{tabular}

COMP: componente.

Los resultados de la tabla anterior fueron utilizados para establecer agrupamiento de morfotipos en función a las variables (fosforo, numero de nódulos, $\mathrm{CIC}$ ), mediante el análisis de clúster aglomerativo. Teniendo en cuenta los resultados del análisis de clúster aglomerativo, (Fig. 4), se observa que existen 4 grupos morfológicos de bacterias del género Rhizobium con características homogéneas y de confiabilidad del $88 \%$ relación a las variables analizadas.

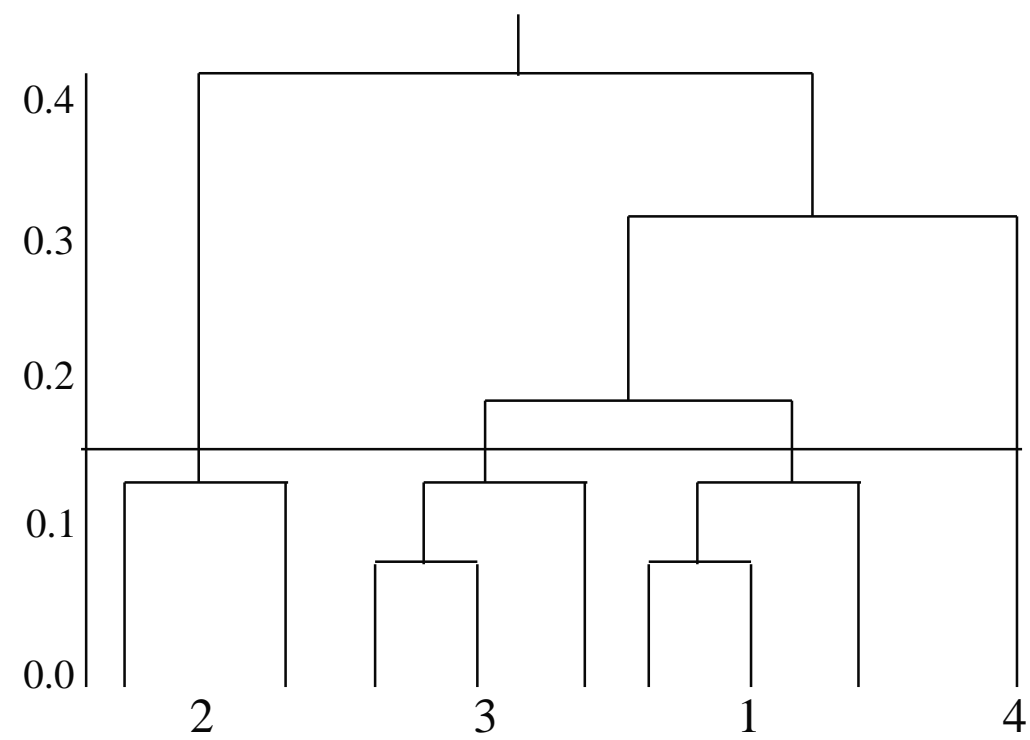

Figura 4. Análisis de Clúster aglomerativo de agrupamiento de los morfotipos en relación a las variables (fósforo, número de nódulos y $\mathrm{CIC}$ ) 
En la tabla 5, se describen las características homogéneas de los 4 grupos de morfotipos clasificados mediante el análisis de componentes principales, en función de las variables clasificadas (fosforo, numero de nódulos, CIC. En el grupo 1, se encuentran los morfotipos mas variable; están presenten cuando existen niveles muy altos de fósforo, una capacidad de intercambio catiónico $(\mathrm{CIC})$ moderada en los suelos, poseen un número de nódulos de bajo a medio. El grupo 2 es el más homogéneo células de forma alargadas, las cuales están asociadas con niveles de $\mathrm{P}$ excesivamente altos, alta $\mathrm{CIC}$ y bajo $\mathrm{N}^{\circ}$ de nódulos. El grupo 3 es similar al grupo 2, forman células alargadas) y elipsoidales, están asociados a niveles de $\mathrm{P}$ muy altos. CIC alta y con un número de nódulos bajo. El grupo 4 se encuentran morfotipos formando células esferoidales, con un alto número de nódulos, y presentes cuando en los suelos existen alto niveles de P y una CIC media.

Tabla 5. Descripción de las características homogéneas de los grupos obtenidos a partir de los resultados del Análisis de Componentes Principales

\begin{tabular}{|c|c|c|c|c|c|}
\hline Grupo & Muestra & № Nódulos & $\mathbf{P}$ & CIC & Morfotipo \\
\hline \multirow{4}{*}{1} & M006a & 9 & 83.46 & 16.5 & 1 \\
\hline & M006b & 9 & 83.46 & 16.5 & 5 \\
\hline & M007 & 6.67 & 72.91 & 19.28 & 2 \\
\hline & M008 & 22.5 & 72.91 & 19.25 & 3 \\
\hline & & & & & \\
\hline \multirow{5}{*}{2} & M001 & 7.67 & 112.31 & 27.5 & 1 \\
\hline & M004 & 6.5 & 117.82 & 26.68 & 2 \\
\hline & M0012 & 13 & 112.31 & 27.5 & 4 \\
\hline & M0013a & 19.33 & 121.93 & 26.95 & 4 \\
\hline & M0013b & 19.33 & 121.93 & 26.95 & 4 \\
\hline \multirow{4}{*}{3} & M002 & 4.67 & 92.74 & 25.8 & 1 \\
\hline & M003 & 8.33 & 90.96 & 28.88 & 4 \\
\hline & M010 & 4.67 & 93.55 & 17.93 & 4 \\
\hline & M011 & 21.67 & 96.2 & 23.65 & 2 \\
\hline 4 & M009 & 22 & 4353 & 1925 & 3 \\
\hline
\end{tabular}


En la fig. 5, se observa el agrupamiento de los 4 grupos de morfotipos encontrados en relación a las variables clasificadas (fósforo, CIC y número de nódulos) y guardando relación a las características mostradas en la tabla 5 .

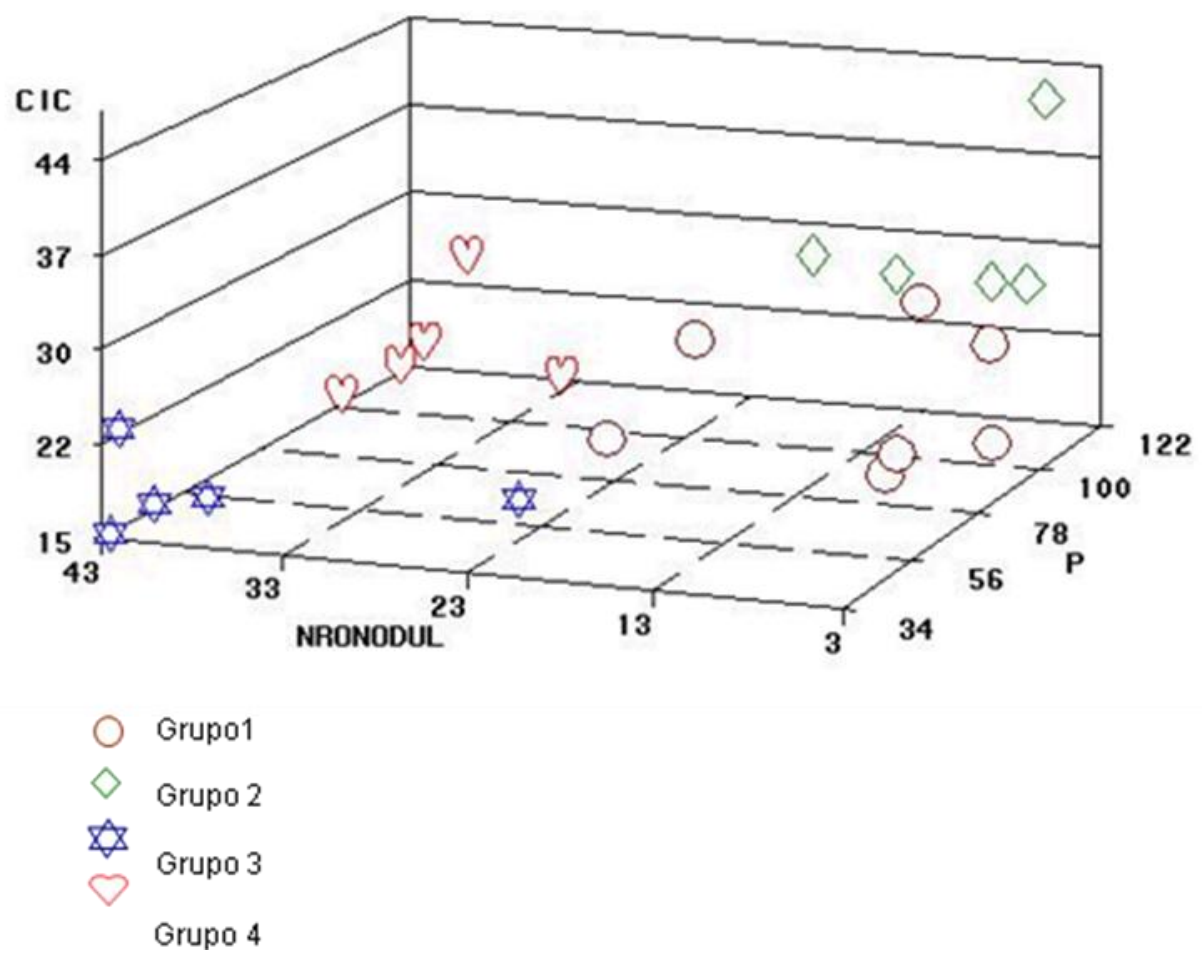

Figura 5. Agrupamiento de los morfotipos con relación a las componentes clasificatorias $(\mathrm{P}$, número de nódulos y $\mathrm{CIC}$ )

La tabla 6 muestra los resultados obtenidos de la densidad poblacional mediante técnica de conteo de colonias en placa de los diferentes morfotipos aislados. La densidad en UFC/mL, osciló de $11 \times 10^{8}$ para el morfotipo M012, aislado de la zona 5 a $3.0 \times 10^{8}$ para M004 en la zona 2. Teniendo en cuenta los promedio, la zona que mostro una mayor densidad poblacional correspondió a la zona 3, perteneciente al corregimiento de Pita Abajo, en contraste la a zona de menor densidad $\left(15^{\star} 10^{8} \mathrm{UFC} / \mathrm{ml}\right)$ la cual correspondió a los morfotipos aislados en suelos del corregimiento de Santa Lucía. 
Tabla 6. Densidad poblacional de morfotipos de Rhizobium en UFC/mL.

\begin{tabular}{|c|c|c|c|}
\hline Zona & Aislamiento & $\begin{array}{l}\text { Conteo } \\
\text { (UFC/ml) }\end{array}$ & $\begin{array}{l}\text { Promedio } \\
\text { (UFC/ ml) }\end{array}$ \\
\hline \multirow{3}{*}{1} & MOO1 & $19 \times 10^{8}$ & \multirow{3}{*}{$18 \times 10^{8}$} \\
\hline & MOO2 & $25 \times 10^{8}$ & \\
\hline & MOO3 & $10 \times 10^{8}$ & \\
\hline \multirow{3}{*}{2} & MOO4 & $30 \times 10^{8}$ & \multirow{3}{*}{$21 \times 10^{8}$} \\
\hline & MOO8 & $20 \times 10^{8}$ & \\
\hline & MOO9 & $14 \times 10^{8}$ & \\
\hline \multirow{3}{*}{3} & MOO6a & $24 \times 10^{8}$ & \multirow{3}{*}{$22 \times 10^{8}$} \\
\hline & MOO6b & $30 \times 10^{8}$ & \\
\hline & MOO7 & $12 \times 10^{8}$ & \\
\hline \multirow[b]{2}{*}{4} & MO13a & $15 \times 10^{8}$ & \multirow[b]{2}{*}{$15 \times 10^{8}$} \\
\hline & MO13b & $16 \times 10^{8}$ & \\
\hline \multirow{3}{*}{5} & MO10 & $20 \times 10^{8}$ & \multirow{3}{*}{$16 \times 10^{8}$} \\
\hline & MO11 & $18 \times 10^{8}$ & \\
\hline & MO12 & $11 \times 10^{8}$ & \\
\hline
\end{tabular}

En la Fig. 6, se detallan las características macroscópica y microscópica de los 5 grupos de morfotipos con características similares al género Rhizobium aislados a partir de nódulos de Teramnus volubilis en condiciones de fincas ganaderas del municipio de Tolú. 


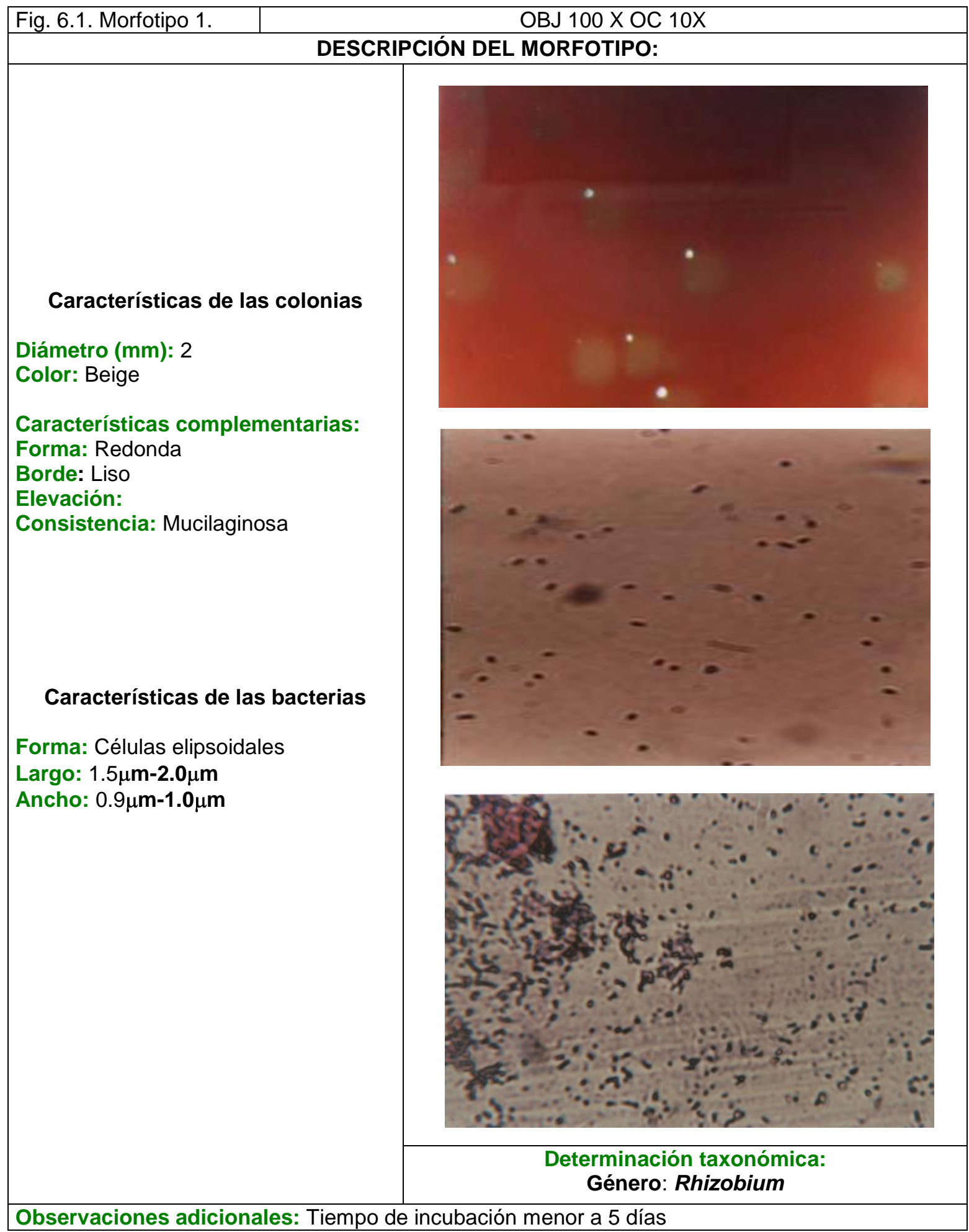




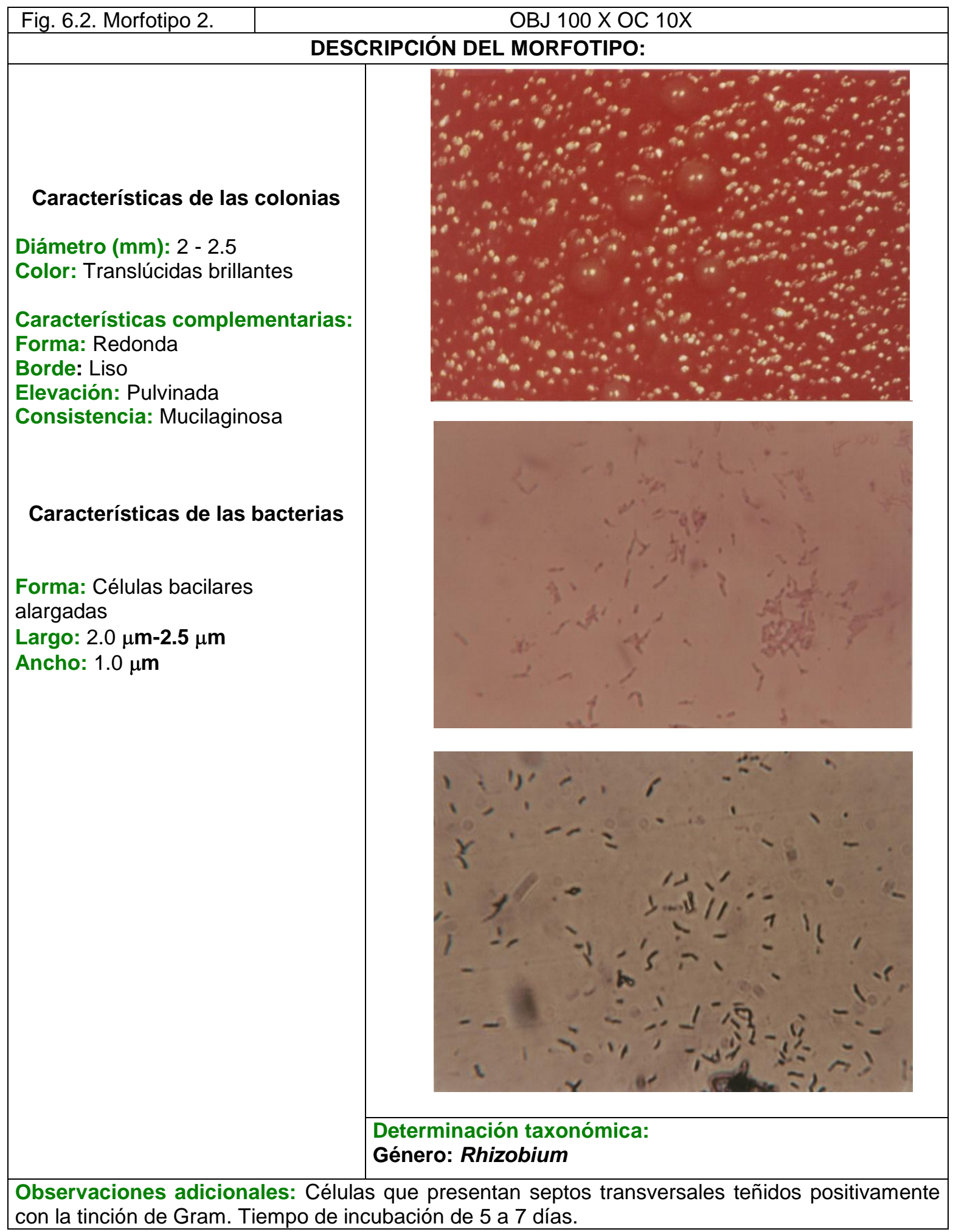




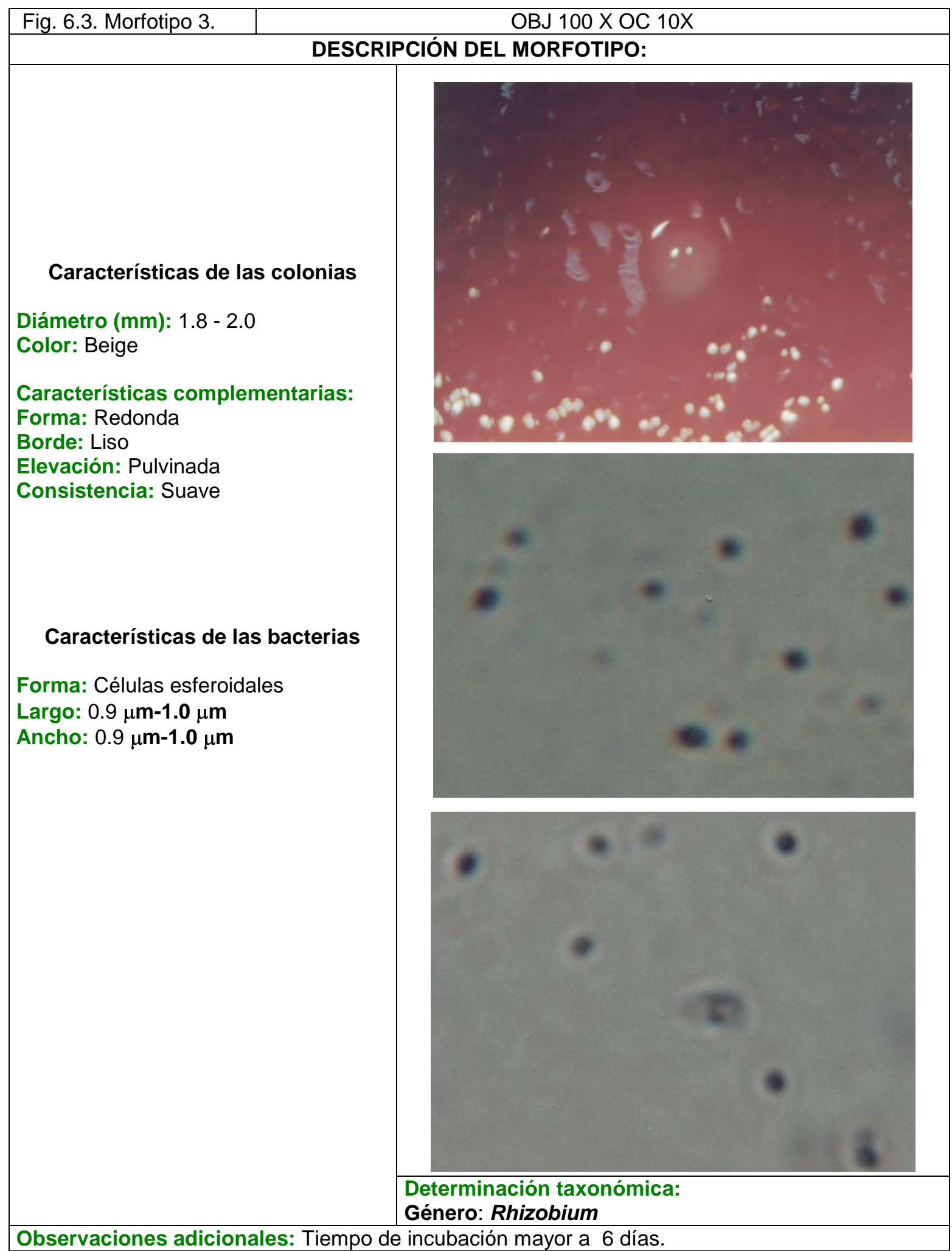




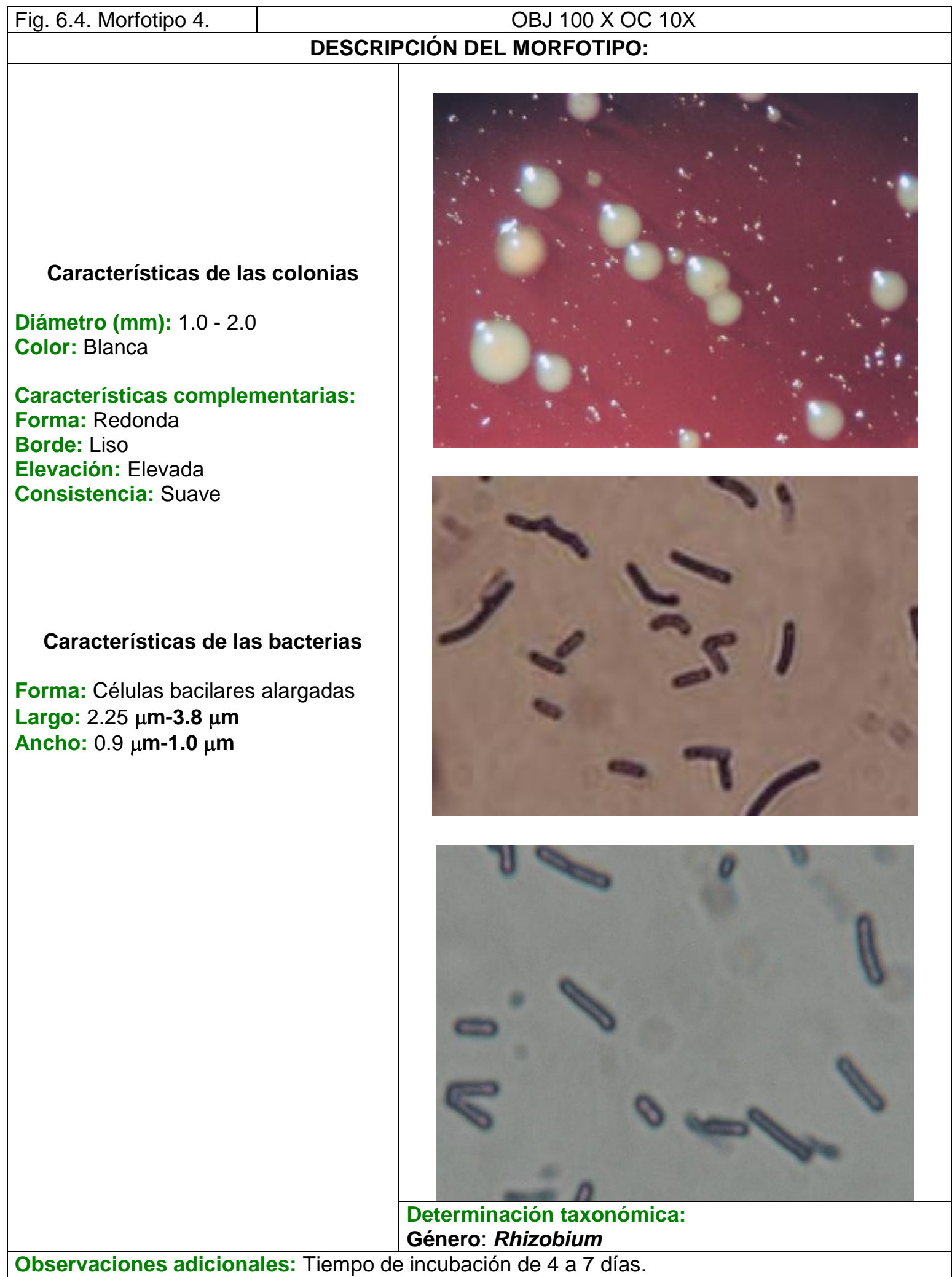

Fig. 6.5. Morfotipo 5. OBJ $100 \times$ OC $10 X$ 


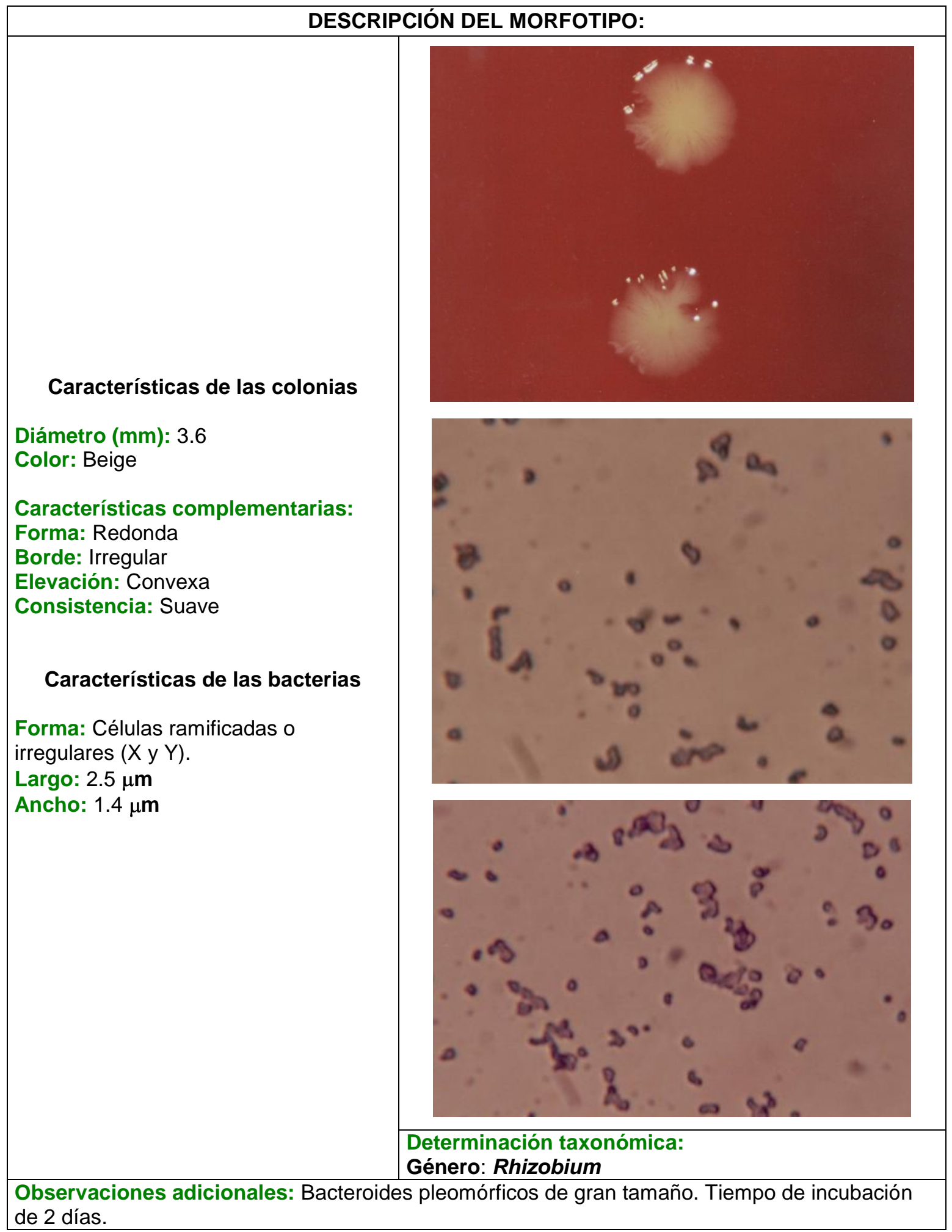

Figura 6. Morfotipos (1-5) con características similares al género Rhizobium aislados a partir de nódulos de Teramnus volubilis Sw en condiciones de fincas ganaderas del municipio de Tolú 
Del total de muestras analizadas, se obtuvieron 28 aislamientos de los cuales 14 resultaron con características similares al género Rhizobium y los cuales de acuerdo a los análisis anteriores fueron agrupados en 5 morfotipos. En la fig. 7 , se observa el porcentaje de participación de cada morfotipos aislamientos en el presente estudio. En la fig, se muestra que el morfotipo 4 presento el mayor porcentaje de participación (35.7\%) con relación al resto de morfotipos encontrado.

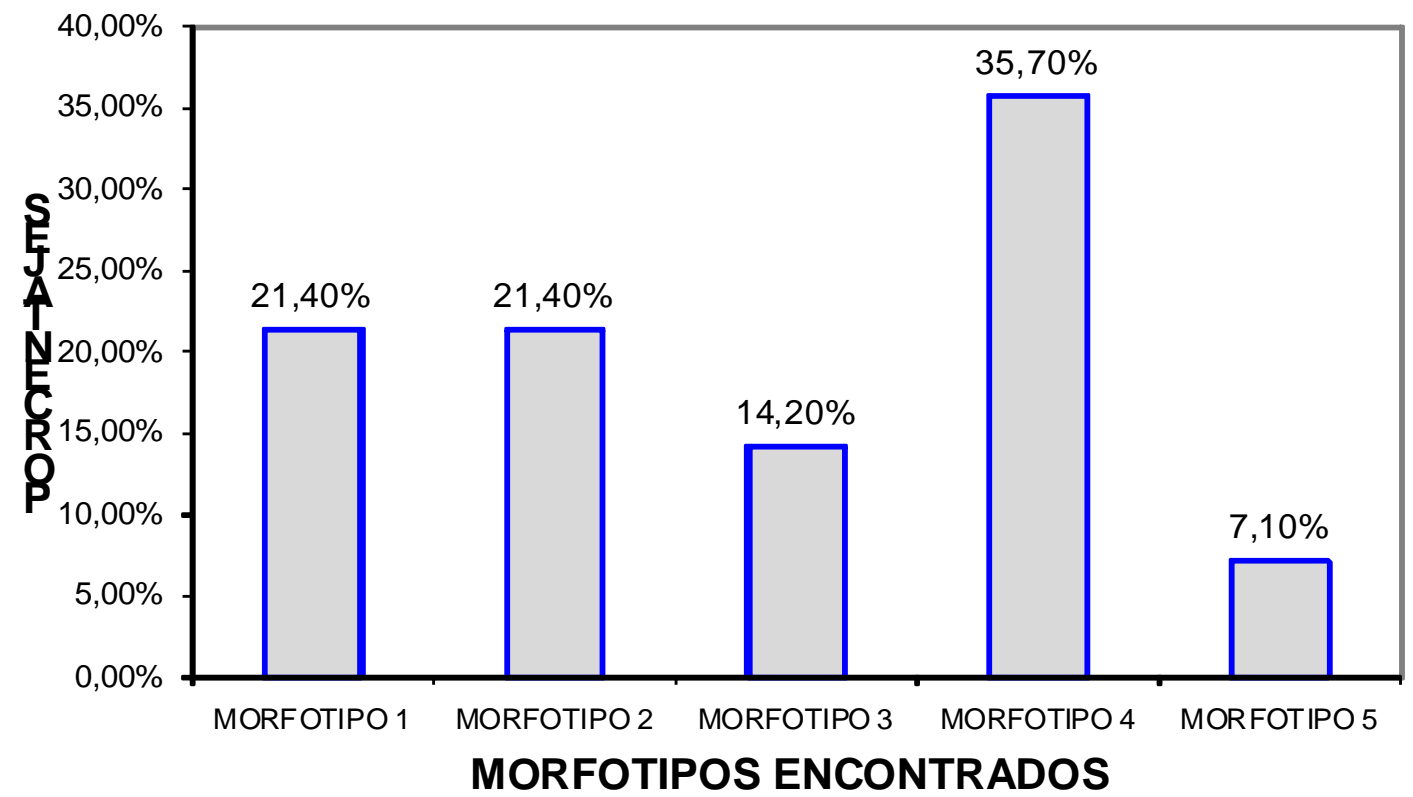

Figura 7. Distribución porcentual de los 5 morfotipos de Rhizobium asociados a T. volubilis en el municipio de Tolú

\section{Discusión}

La especie de leguminosa Teramnus volubilis es muy abundante y se caracteriza por permanecer verde durante la época de lluvias, en suelos con buena retención de humedad, resiste la sequía de 3 a 4 meses inclusive el pisoteo, tiene una alta producción de semillas, sobre todo entre los meses de febrero a Marzo. La especie de pasto con gran presencia es angletón (Dichanthium aristatum), a la cual Teramnus volubilis se asocia muy bien. La predominancia de esta leguminosa se explica principalmente por el alto contenido de fósforo $(\mathrm{P})$ de estos suelos, ya que su capacidad competitiva se 
ve mejorada por este en relación con las gramíneas asociadas (SHERMAN et al., 1991).

Estos suelos presentan niveles de acidez moderada lo que permite el desarrollo de Rhizobium, ya que los suelos demasiados ácidos pueden originar problemas de nutrición mineral (deficiencias de $\mathrm{Ca}, \mathrm{Mg}$ y $\mathrm{K}$ ), tanto en Rhizobium como en la leguminosa hospedante (SHERMAN et al., 1991; MAYEA et al., 1998; JIMÉNEZ y LAMO, 1998; PÉREZ- GALDONA y KAHN, 1994). Es frecuente encontrar deficiencia de los elementos deficiencia de $P$ y $\mathrm{N}$, lo cual causa una reducción en la fijación de $\mathrm{N}_{2}$ por efectos específicos en la iniciación y crecimiento del nódulo y la actividad de la enzima nitrogenasa, presente en la célula de especies de Rhizobium (MONTES, 1999). Uno de los motivos del escaso crecimiento de ciertas leguminosas en los suelos ácidos puede ser la reducida absorción de Molibdeno (Mo) (MAYEA et al., 1998; JIMÉNEZ y LAMO, 1998; FREY y BLUM, 1994). Sin embargo el crecimiento de la leguminosa y la nodulación son satisfactorios en pH 5.4 a 7.0 (FLECHTER, 1958). Esto concuerda con lo encontrado en el presente estudio, ya que en promedio el número de nódulos fue significativamente alto, asociado también a un tamaño mediano de estos.

La abundancia de nódulos con una coloración interna blanca y asociada con raíces noduladas, se explica principalmente por la falta de Molibdeno (Mo) según lo expuesto por MAYEA et al., (1998) y MARTíNEZ -VIERA (1986), ya que este es escaso, se forman nódulos, menos eficientes y su estructura se asemeja a la de los nódulos inactivos, debido a que en condiciones de suelos ácidos es difícil la absorción de este nutriente. Sin embargo, la presencia de nódulos con coloración interna roja, se explica por la abundancia de cationes divalentes (Ca y $\mathrm{Mg}$ ), los cuales se encuentran en niveles altos y no permiten una mala viabilidad nodular (MAYEA et al., 1998). Es por esta razón que la CIC (Capacidad de Intercambio Catiónico) es una de las características físico-químicas del suelo que clasifican o agrupan los morfotipos obtenidos, dilucidando una importante relación entre esta y el número de nódulos, sobre todo porque estos suelos tienen una CIC alta.

Aunque recientes estudios realizados por CABA et al., (2001) señalan que la planta es la que controla principalmente el numero de nódulos, mediante un mecanismos de autorregulación, este también es controlado por factores externos como la presencia de nitratos en el suelo. Las raíces de leguminosas pobremente noduladas o con pocos nódulos pueden deberse a 
una abundancia de nitrógeno combinado en el suelo, el cual inhibe la nodulación (NUTMAN, 1956). Por su parte COYNE (2000) afirma que el número de nódulos depende de la fertilidad de el suelo, es decir, de la cantidad de nutrimentos minerales $(\mathrm{P}, \mathrm{K}, \mathrm{Mg}, \mathrm{Ca})$ presentes en él. Esto concuerda con los resultados obtenidos en el presente estudio, donde encontró que la presencia de un mayor número de nódulos se asocia a altos contenido de $\mathrm{P}$ principalmente y también a altos niveles de $\mathrm{Mg}, \mathrm{K}$ y $\mathrm{ClC}$. Además los grandes nódulos son casi siempre escasos y los pequeños generalmente abundantes y ampliamente dispersos en la raíz. (SHERMAN et al., 1991; COYNE 2000). Según NUTMAN (1958), la infección por parte de Rhizobium se produce en unas cuantas zonas bien separadas de la raíz y no al azar, y el número de pelos infectados varía según la especie de leguminosas y su capacidad de desarrollo de raíces laterales, lo cual depende del genotipo de cada planta.

Adicionalmente, los altos niveles de $\mathrm{P}$ tienden a incrementar la absorción de $\mathrm{Mn}$, el cual causa un descenso en el número y el volumen de los nódulos, pero este efecto se ve contrarrestado por la presencia de calcio (SHERMAN et al., 1991; PÉREZ y TORRALBA, 1997). Esto se refleja en aquellos aislamientos asociados a suelos con altos contenidos de $\mathrm{P}$ pero un № de nódulos no tan alto. Sin embargo, el $\mathrm{P}$ aumenta el peso seco del nódulo al elevarse sus niveles en el suelo y estimula además el aumento del № de nódulos y el porcentaje de fijación de nitrógeno. Además, la moderada presencia de este elemento en los suelos de las fincas ganaderas, favorece la actividad del $\mathrm{K}$, el cual aumenta el número y tamaño de los nódulos (LYNCH y SEARS, 1951).

Debido al papel decisivo que juega el $\mathrm{P}$ en el establecimiento y desarrollo de Rhizobium y la leguminosa, es la principal característica clasificatoria de los morfotipos en cuanto a la relación que estos presentan con las propiedades físico-químicas del suelo y de la nodulación. Los agrupamientos que se formaron teniendo en cuenta estas características, muestran una gran variabilidad sobre todo el primer grupo que presenta casi todos los morfotipos. Esto sugiere que la morfología de la bacteria, es decir el morfotipo es independiente de las características físico-químicas del suelo y más bien depende del genotipo de la bacteria de Rhizobium propio de cada cepa. Según JORDAN y COULTER (1965) los bacteroides natural o artificialmente producidos sufren un deterioro en la síntesis de proteína y de la pared celular. La alteración de las capacidades de síntesis y la posible 
formación de material anormal en la pared celular, incapaz de conferir rigidez, pueden ser la causa de la morfología externa. Las propiedades físicoquímicas están más relacionadas con la capacidad de nodulación de la leguminosa, el desarrollo del nódulo y la fijación de nitrógeno.

En cuanto a la clasificación de los aislamientos de Rhizobium en 5 morfotipos, se determino que la forma de la bacteria es la característica más relevante y por tanto clasificatoria, debido a la gran variabilidad de la misma, ya que según los estudios de DART y MERCER (1966) algunas células bacterianas de Rhizobium se expanden muy poco a medida que se desarrolla el nódulo y retienen su forma bacilar, pero otras se expanden enormemente y pierden dicha estructura. De estos dos tipos diferentes de desarrollo de las células se derivan, morfológicamente hablando, varios tipos de bacteroides o células bacterianas de Rhizobium: esferoides, elipsoidales, ramificadas 0 irregulares (Formas curvas, $x, y$ ) 0 en forma de bacilo con numerosos tipos intermedios (alargados, medianos) (BERGENSEN 1957; SPAINK 2000), sin embargo, independientemente de su morfología los bacteroides tienen todos la misma función dentro de él nódulo.

El largo o longitud de la bacteria ayuda a definir también la morfología de la misma, ya que dependiendo de este la bacteria puede ser esferoidal si su longitud es pequeña, incluso igualando su ancho, si su largo es mediano puede ser elipsoidal y si su longitud es bastante grande $(>2.8 \mu \mathrm{m})$ pueden ser irregulares o pleomorficos ya que según COYNE (2000) estas formas pueden llegar a ser hasta 40 veces más grandes que los bacilos a partir de los que se desarrollan. El color es la característica microscópicas o de las colonias más importantes según nuestro análisis ya que es la que mas variabilidad presenta, encontrándose, traslúcidas, semitranslúcidas, blancocrema y blancas. Las traslucidas y semitraslúcidas se observan así debido a la monocapa de liposacaridos (lípido $\mathrm{A}$, núcleo sacáridos y antígeno O) que produce el Rhizobium, la cual se proyecta al exterior y le da una coloración transparente y una consistencia mucosa o mucilaginosa (SPAINK et al., 1998). Esto se produce más abundantemente si el medio contiene manitol el cual estimula su producción (VARGAS, 1969). Algunos de nuestros aislamientos producen menos cantidad de lipopolisacaridos dando una coloración que vario de beige a blanca.

Las características de los aislamientos, concuerdan con los resultados de investigaciones como DART y MERCER (1996), SPAINK (2000) y COYNE 
(2000), ya que estos presentaban consistencia mucosa por los lipopolisacáridos y las formas de las bacterias obtenidas variaron desde esferoidales a bacilares alargadas, incluyendo irregulares. El resto de características tomadas se consideraron como complementarias ya que el análisis estadístico considero que su variabilidad no era mayor que la de las anteriores, estas eran más bien uniformes para la mayoría de los aislamientos y no se trataron como relevantes para obtener la clasificación o agrupamiento de los morfotipos.

\section{Agradecimientos}

Los autores expresan sus agradecimientos al laboratorio de microbiología de la Universidad de Sucre por la realización del experimento.

\section{Referencias}

AGUILERA, DM. 2005. Documento de trabajo sobre Economía Regional: La Economía del Departamento de Sucre: Ganadería y Sector Público. Cartagena de India: Banco de la República; 2005. http://www.banrep.gov.co/documentos/publicaciones/pdf/DTSER-43.pdf

ALAMI, Y.W.; ACHOUAK. C.L.; THEULIN, M. 2000. Rhiizosphere soil aggregation and plant growth promotion of sunflowers by an expolysacharide producing Rhizobium sp. Strain isolated from sunflower roots. Applied and environmental microbiology 66 (8):3393-3398.

BERGERSEN, F.J.1957. Some features of the forms of Rizhobium found within the host cell of legume root nodule. Soil sci. 1: 78(1):213-234.

BERMÚDEZ. L.A. 1973. Leguminosas espontáneas de posible valor forrajero en Colombia. Ministerio de agricultura. ICA. Colombia.

CABA, J.M.; POVEDA, J.L.; LIGERO. F. 2001. Control de la nodulación en las leguminosas: Implicación de las fitohormonas, disponible en:http://193.146.205.198/sefin/Ligero.html 
CENTRO INTERNACIONAL DE AGRICULTURA TROPICAL (CIAT). 1987. Simbiosis leguminosas-Rhizobium. Manual de métodos evaluación, selección y manejo. Sección microbiología de suelos. Programa de pastos tropicales y Programa de fríjol. CIAT, Cali-Colombia.

COYNE, M. 2000. Microbiología del suelo: un enfoque exploratorio. Editorial Paraninfo. España.

DART, P.J.; MERCER, F.V. 1966. Fine structure of bacteroids in root nodules of Vigna sinensis, Acacia longifolia, Viminaria juncea and Lupinus anguatifolius. J. Bact. 91:1314-1319.

ERDMAN, L.W. 1968. Inocule sus leguminosas. Agricultura de las Americas, U.S.A. $17(6): 45-48$.

ESPITIA, F.G.; MARTINEZ, E. 2003. Identificación de géneros de hongos formadores de micorrizas arbusculares (H.M.A) en las especies de pasto colosoana (Bothrichloa pertuosa (L) $A$.camus) y àngleton (Dichanthium benth) en los municipios de corozal y Tolú, departamento de Sucre.Trabajo de grado, Departamento de Biología, Universidad de sucre, Colombia.112 p.

FLETCHER, W.W. 1958. The effect of $\mathrm{pH}$ on nodulation of Trifolium pratense growing in Liquid culture. Phytopatology 10:129-134.

FREY, S.D.; BLUM, L.K.. 1994. Effect of $\mathrm{pH}$ on competition for nodule occupancy by type I and type II strains of Rhizobium leguminosarum b.v. phaseoli. Plant Soil 163: 157-164. http://www.springerlink.com/content/f675874m24138364/.

INSTITUTO GEOGRAFICO AGUSTIN CODAZZI (IGAC). 1998. Estudio general de suelos y zonificación de tierras. Departamento de sucre. Ediciones IGAC. Bogotá.

JIMÉNEZ, R.; LAMO, J. 1998. Agricultura Sostenible. Condición Agrofuturo Life. Ediciones Mundi - Prensa. España.

JORDAN, D.C.; COULTER, W.H. 1965. On the cytology and synthetic capacities of natural and artificial produced bacteroids of Rhizobium spp. J. Gen. Microbial 5:592-595.

KENNEDY, A.C.; SMITH, K.L. 1995. Soil microbial diversity and the sustainability of agricultural soils. Plant soil, 170: 75-86. 
LYNCH, D.L.; SEARS, O.H. 1951. Differential response of Strains of Lotus nodule bacteria to soil treatment practices. Proc. Soil. Sci. Soc. Am. 15: 176180.

MARTINEZ, T. J.; LOPEZ, I. 2000. Rhizobium y su destacada simbiosis con plantas.198p.

MARTíNEZ-VIERA, R. 1986. Ciclo biológico del nitrógeno. Cap. I y II. Ed. Científico técnica. La Habana.

MAYEA, S.; CARONE, M.; R.NOVO, B.I.; SILVEIRA, E.; SORIA. M.; MORALES. Y.; VALIÑO, A. 1998. Microbiología Agropecuaria. Tomo II. Ed. Félix Varela. La Habana.

MONTES, L. 1999. Efecto del fósforo en la nutrición nitrogenada del fríjol común $(P$. vulgaris). Disponible http://www.cartuja.csic.es/SEFV99/abstracts/nutricion/s.3-6.html.

NUTMAN, P.S. 1956. The influence of the legume root nodule symbiosis. A comparative study of host determinants and functions. Biol. Rev. 31:109-151.

PERALTA, O. 2002. Manejos de pasturas, información básica formación $Y V Y$, ediciones limusa. Paraguay.

PEREZ, S.; TORRALBA, A. 1997. La fijación del nitrógeno por los seres vivos. Sciptus Naturae, seminario 21(01):21p.

PEREZ-GALDONA, R.; KAHN, M.L. 1994. Effects of organic acids and low $\mathrm{pH}$ on Rhizobium meliloti 104A14. Microbiology140: 1231-1235. http://mic.sgmjournals.org/cgi/reprint/140/5/1231.pdf.

RAMÍREZ, M. 1992. Técnicas de microbiología de suelos aplicadas a la fijación simbiótica de nitrógeno. Sección Recursos Naturales Instituto Colombiano Agropecuario. Bogotá.

SHERMAN, P.J.; CAMEROM, D.G.; RIVEROS, F. 1991. Leguminosas Forrajeras Tropicales. Organización de la Naciones Unidas para la agricultura y alimentación (FAO). Colección FAO; Producción y Protección Vegetal № 2. Roma.

SPAINK, H. P. 2000. Root Nodulation and Infections Factors Produced by Rhizobial Bacteria. Annual Review of Microbiology 54:257-288. http://www.ufv.br/dbv/pgfvg/BVE684/htms/pdfs revisao/estresse/infectionfact ors.pdf. 
STODDARD, C.D. 1975. Leguminosas: Mayores y Mejores cosechas, como aprovechar el nitrógeno del aire. Agricultura de las Américas 8(24): 28-29.

VALENZUELA, M.E.; SILVESTRES, J.H. 1991. Microbiología de alimentos. UNISUR, Bogotá.

VARGAS, E. 1969. Aspectos Microbiológicos de la Fijación Simbiótica de Nitrógeno por el Rhizobium. Instituto geográfico "Agustín Codazzi". Bogotá.

VILORIA, HJ. Documento de trabajo sobre economía regional: La ganadería bovina en las Ilanuras del Caribe Colombiano. Cartagena de Indias: Banco de la República; 2003. http://www.banrep.gov.co/documentos/publicaciones/pdf/DTSER-43.pdf.

WEAVER, R.W.; GRAHAM, P.H. 1994. Legume nodule Symbionts. En Methods of Soil Analysis, Part 2: Microbiological and Biochemical Properties, R. W. WEAVER y Cols. (eds) Madison, WI: Soil Science Society of America. Nueva York. 